\title{
Non-Invasive Predictors of Response to Tamsulosin for Benign Prostatic Obstruction
}

\author{
Mohammad Shoaib ${ }^{1}$, Muhibullah Bangash ${ }^{1}$, Wajahat Aziz ${ }^{2}$, M Hammad Ather ${ }^{2}$ \\ 1. Section of Urology, Department of Surgery, Aga Khan University Hospital, Karachi, PAK 2. Section of Urology, \\ Department of Surgery, Aga Khan University, Karachi, PAK
}

Corresponding author: Mohammad Shoaib, shoaib.mohammad@aku.edu

\section{Abstract \\ Objectives}

To identify non-invasive predictors of response to tamsulosin $0.4 \mathrm{mg}$ in patients with benign prostatic obstruction (BPO).

\section{Methods}

Males $\geqslant 50$ years of age with lower urinary tract symptoms (LUTS) suggestive of BPO for over three months were included in the study. We assessed change in the mean International Prostate Symptom Score (IPSS) and maximum flow rate (Qmax) after six weeks of medical therapy. Clinical and uroflowmetry parameters were compared between two groups of patients with $>25 \%$ vs. $<25 \%$ change in the IPSS after treatment. Preand post-treatment post-void residue (PVR), Qmax, and IPSS were compared by independent t-test, univariate/multivariate regression analysis.

\section{Results}

A total of 121 patients were included. At presentation, the mean prostate size was $35.7 \pm 12.2$ grams and the mean IPSS was $16.3 \pm 4.8$. Improvement in the mean IPSS was 7.83, with more marked improvement in storage compared to voiding LUTS (5.26 vs. 2.57). Majority (58\%) had a quality of life (QoL) score of 4-5 at presentation whereas after 6-weeks of medication (83.5\%) had a QoL score of 0-2. Treatment failure was noted in 11 (9.1\%) patients. IPSS was higher and Qmax was lower at the time of presentation in patients who had $<25 \%$ improvement. However, the two groups were identical on the basis of demographic and other factors (BMI, age, prostate size, PVR).

\section{Conclusion}

Moderate LUTS secondary to BPO responds favourably to alpha-blocker (tamsulosin $0.4 \mathrm{mg}$ ) treatment. Uroflowmetry (UFM) parameters, that is, Qmax and IPSS are important factors in predicting short-term response to medical therapy.

Review began 02/08/2021 Review ended 02/09/2021 Published 02/15/2021

\section{๑) Copyright 2021}

Shoaib et al. This is an open access article distributed under the terms of the Creative Commons Attribution License CC-BY 4.0., which permits unrestricted use, distribution, and reproduction in any medium, provided the original author and source are credited.
Categories: Urology

Keywords: benign prostatic obstruction, alpha-blockers, predictors

\section{Introduction}

Benign prostatic obstruction (BPO) is a progressive disease often observed in men over 50 years of age. Enlargement of the prostate does not affect all men in a similar fashion [1]. BPO leads to a deterioration in the quality of life by disturbing normal activities such as sleep, and may cause complications such as recurrent UTIs, bladder stones or acute urinary retention. The most commonly performed surgical intervention for BPO is transurethral resection of the prostate. However, it is associated with short and long term morbidity [2]. Currently, medical treatment with alpha-blockers, 5-alpha-reductase inhibitors (5-ARIs) either alone or in combination has become the first line of therapy. Alpha-blockers, act by relaxing the prostatic smooth muscle and improve urination, are most commonly used for BPO patients.

Clinical and investigational workup in the evaluation of benign prostatic enlargement, besides baseline workup, include the International Prostate Symptoms Score (IPSS), uroflowmetry and post-void residual (PVR) urine or urodynamic studies [3].

An interventional urodynamic study, in particular pressure flow study, is the gold standard in the diagnosis of BPO secondary to BPH. Predictors of response to therapy are useful in stratifying patients for first-line medical versus surgical treatment [4]. These predictors can be classified as invasive and non-invasive. In some men, the symptoms are difficult to manage with medical therapy while others respond remarkably well to alpha-blockers + 5ARIs. This may be the result of different morphological characteristics of prostatic enlargement. Morphologically four types of prostatic enlargement are described such as isolated lateral or 
There are several non-invasive tests available for the diagnosis of BPO in order to avoid the morbidity associated with invasive urodynamics. However, there is uncertainty concerning the diagnostic accuracy of these tests. Most of the guidelines endorse these tests as "mandatory" or "recommended" in the clinical evaluation of men with BPO. In a systematic review by Malde et al [6], authors noted high sensitivity and specificity of evaluation of detrusor wall thickness, near-infrared spectroscopy and the penile cuff test in diagnosing BPO.

We conducted this study to assess improvement in IPSS and determine predictors of urinary retention and the need for intervention in patients on medical treatment with alpha-blocker tamsulosin hydrochloride. Results of this study will help in counselling of management and the need for intervention.

\section{Materials And Methods}

We performed a cross-sectional study at the Department of Urology in a University Hospital. After ethical review committee approval, patients above 50 years of age presenting with lower urinary tract symptoms (LUTS) suggestive of BPO for more than three months were included. We excluded patients already on any medical therapy, patients with bladder stone, urinary tract infection, neurogenic bladder or urethral stricture. Patients who had an intervention for prostatic obstruction previously or who were unable to perform uroflowmetry (UFM) were also excluded. Data were collected over a period of nine months. Nonprobability consecutive sampling technique was employed. The primary outcomes were improvement in mean IPSS and Qmax after six weeks. Secondary outcomes were urinary retention or need for surgery. The IPSS consists of seven questions that deal with voiding symptoms (incomplete emptying, intermittency, weak stream and straining to void) and storage symptoms (frequency, urgency and nocturia) in addition to another question, looking at the effect on the quality of life (QoL).

Data were analysed using SPSS version 25 (IBM Corp., Armonk, NY). Descriptive analyses for quantitative variables were reported as mean and $\mathrm{SD}$, categorical variables such as basic demographic, clinical and other desired characteristics were reported as frequency and percentages. The pre- and post-treatment PVR, Qmax, and IPSS were reported as mean \pm SD and were assessed by the independent t-test. P-value of less than 0.05 was considered statistically significant.

Response to medical therapy was seen in terms of improvement in IPSS at six weeks. Responders were defined as an overall improvement of $\geqslant 25 \%$ in IPSS score after six weeks. Predictors of response were identified with logistic regression analysis.

\section{Results}

A total of 121 patients were included in our study. Mean age was $62.87 \pm 8.78$ and mean BMI was $26.05 \pm$ 3.78. Thirty-five (29\%) men were diabetic. The mean prostate size was $35.7 \mathrm{~g} \pm 12.2$. Most patients $(80 \%)$ had an IPSS of 8-18 (moderate score) on presentation.

In Table 1, the pre- and post-treatment parameters are described. Mean improvement in IPSS of 7.83 was noted after six weeks of tamsulosin, with more marked improvement in storage symptoms as compared to voiding symptoms (5.26 vs. 2.57). More than half of the patients (58\%) had a QoL score of 4-5 (mostly unsatisfied/unhappy) at presentation whereas after six weeks of medication $83.5 \%$ had a QoL score of $0-2$ (delighted/pleased/mostly satisfied). Treatment failure was noted in 11 (9.10\%) patients. One patient developed urinary retention and the remaining 10 patients did not have any improvement in symptoms and were advised interventional treatment. 


\section{Cureus}

\begin{tabular}{|c|c|c|c|}
\hline Variable & Pre-treatment & Post-treatment & P-value \\
\hline IPSS & $16.27 \pm 4.78$ & $8.45 \pm 5.37$ & 0.001 \\
\hline IPSS storage & $9.28 \pm 2.20$ & $4.02 \pm 2.48$ & 0.001 \\
\hline IPSS voiding & $7.0 \pm 3.10$ & $4.42 \pm 3.11$ & 0.001 \\
\hline QoL & $4.14 \pm 1.11$ & $1.81 \pm 1.16$ & 0.001 \\
\hline PVR & $77.09 \pm 57.24$ & $33.74 \pm 34.24$ & 0.001 \\
\hline Qmax & $10.41 \pm 3.45$ & $14.69 \pm 5.53$ & 0.001 \\
\hline Qavg & $5.01 \pm 3.45$ & $8.02 \pm 3.52$ & 0.001 \\
\hline
\end{tabular}

\section{TABLE 1: Pre-treatment and post-treatment parameters.}

IPSS: International Prostate Symptoms Score; QoL: quality of life; PVR: post-void residue.

The group with $>25 \%$ improvement in IPSS score was compared with those who had $<25 \%$ improvement, no significant difference was found with regards to age, BMI and prostate size. However, a higher IPSS and PVR and lower Qmax and Qavg at the time of presentation were significant predictors of poorer response $(<25 \%$ improvement in IPSS) (Table 2). On multivariate regression analysis, Qmax and IPSS at the time of presentation were found to be the only significant predictors of response to Tamsulosin (Table 3).

\begin{tabular}{|c|c|c|c|}
\hline & Not improved & Improved & \\
\hline & $\mathrm{N}=18(15 \%)$ & $\mathrm{N}=103(85 \%)$ & \\
\hline Age & $63.50 \pm 9.87$ & $62.77 \pm 8.52$ & 0.67 \\
\hline BMI & $25.81 \pm 4.02$ & $24.91 \pm 3.74$ & 0.84 \\
\hline Prostate size at presentation & $35.36 \pm 9.42$ & $35.71 \pm 12.68$ & 0.55 \\
\hline PVR at presentation & $106.71 \pm 57.72$ & $71.91 \pm 55.83$ & 0.27 \\
\hline IPSS storage & $11.12 \pm 2.09$ & $8.97 \pm 1.97$ & 0.01 \\
\hline IPSS voiding & $9.77 \pm 4.14$ & $6.50 \pm 2.70$ & 0.04 \\
\hline IPSS pre treatment & $20.89 \pm 5.93$ & $15.47 \pm 4.08$ & 0.01 \\
\hline Quality of Iife & $4.61 \pm 1.20$ & $3.70 \pm 0.80$ & 0.05 \\
\hline Qmax. at presentation & $7.99 \pm 3.29$ & $10.82 \pm 5.31$ & 0.03 \\
\hline Avg. flow at presentation & $3.48 \pm 1.66$ & $5.29 \pm 1.72$ & 0.04 \\
\hline
\end{tabular}

\section{TABLE 2: Comparison of the non-invasive parameters in the groups.}

IPSS: International Prostate Symptoms Score; PVR: post-void residue. 


\begin{tabular}{|c|c|c|c|c|c|c|c|c|}
\hline \multirow[t]{2}{*}{ Variable } & \multicolumn{4}{|c|}{ Univariate analysis } & \multicolumn{4}{|c|}{ Multivariate analysis } \\
\hline & OR & $95 \%$ & & P-value & OR & $95 \%$ & & P-value \\
\hline Post-void residue & 0.96 & 0.96 & 0.99 & 0.02 & 0.99 & 0.98 & 1.00 & 0.66 \\
\hline Prostate volume & 1.00 & 0.96 & 1.04 & 0.91 & & & & \\
\hline Qmax. & 1.51 & 1.84 & 1.94 & 0.01 & 1.28 & 1.01 & 1.62 & 0.03 \\
\hline QoL & 0.34 & 0.19 & 0.62 & 0.01 & 0.98 & 0.41 & 2.33 & 0.96 \\
\hline IPSS & 0.81 & 0.72 & 0.90 & 0.01 & 0.83 & 0.71 & 0.97 & 0.02 \\
\hline
\end{tabular}

TABLE 3: Univariate and multivariate regression analysis.

IPSS: International Prostate Symptoms Score; QoL: quality of life.

\section{Discussion}

Lower urinary tract symptoms are a common presentation in a urological clinic. Significant proportion of these patients have BPO. Alpha-blockers are the mainstay of medical treatment along with lifestyle modifications. Men with detrusor hyperactivity respond better to combination treatment with $\alpha$-blocker with an anticholinergic rather than monotherapy [7]. Combination treatment also makes use of PDE5 inhibitors (even in the absence of erectile dysfunction)[8] and 5 ARIs for larger gland sizes. Nevertheless, a significant proportion of these patients do not respond to the first-line medical treatment. There are multiple reasons for medical treatment failure and prediction of success is helpful in instituting the appropriate treatment on time.

In order to improve the efficacy of medical management, it is important to first and foremost determine whether these symptoms are due to BPO. The gold standard in the diagnosis of BPO is pressure-flow study [9]. However, it is invasive, cumbersome and expensive. Most current guidelines recommend the use of invasive urodynamic only in the select group of patients with equivocal outcome from non-invasive tests or in patients with associated medical conditions that could be the cause of underlying neurogenic bladder dysfunction [10]. Multiple studies have considered predictors of failure of medical therapy using noninvasive tests. These include intra-vesical prostatic protrusion, prostatic urethral angle (PUA), non-invasive urodynamic parameters, PVR, IPSS bladder wall thickness, etc [1,2,11,12,13].

However, in a clinical setting, only limited workup is available at initial presentation as recommended by most urological guidelines, for example, symptom score questionnaires, frequency volume chart (FVC), digital rectal examination(DRE) [14]. In the current study, we attempted to identify factors, which have the potential to predict response to medical therapy.

We found that IPSS at the time of presentation is significant when differentiating potential responders and non-responders to Tamsulosin treatment. However other studies showed that there is a poor correlation of IPSS to bladder outlet obstruction but patient reported symptoms in terms of IPSS do help in deciding appropriate management to some extent [15]. It was interesting to note that improvement in IPSS was less significant in voiding symptoms, which is similar to studies reporting a poor correlation of IPSS with voiding symptoms in patients with BPO $[16,17]$. We also found that Qmax at the time of presentation is also a significant predictor of response to tamsulosin treatment. In our study, Qmax less than 8 did not show improvement in IPSS and can be correlated with BPO. However, one study reported a Qmax $<4.5$ $\mathrm{mL} / \mathrm{sec}$ that was considered obstructed. Similarly, patients with Qmax of more than $11 \mathrm{ml} / \mathrm{sec}$ showed significant improvement in IPSS in our study in comparison to Qmax of $13.8 \mathrm{ml} / \mathrm{sec}$ reported in the literature [18]. In our study, prostate size and PVR are not significant predictors of poor response which is contrary to other studies reporting the prostate size and PVR [1,19] are significant predictors of failure of medical therapy. Although PVR alone cannot predict BPO as these patients do often have detrusor undercontractility $[20,21]$ and the sensitivity and specificity of prostate volume as a predictor of BPO is very low [22].

In our study, only short-term response to medical therapy was assessed and in long-term factors found insignificant, may still be important. We only considered the clinically available workup for stratifying responders and did not include any interventional/investigational factors like urodynamics, which although ideal but usually not required in most patients presenting to a urology clinic. Results of this study will help patients in further deciding their treatment options at least in short term with the help of easily available, safe and quick non-invasive tools. It is a single-center study, so our results may not be applicable to patients who require more extensive workup, for example, those with the underlying neurological condition. 


\section{Conclusions}

In the literature, extensive work has been done and most patients presenting with moderate LUTS secondary to benign prostatic obstruction respond favourably to alpha-blocker treatment. In our study, we also determined that UFM parameters specially Qmax and IPSS are important factors in predicting short-term response to medical therapy.

\section{Additional Information \\ Disclosures}

Human subjects: Consent was obtained or waived by all participants in this study. Ethics Review Committee, Aga khan university hospital, karachi issued approval 2020-3363-8545. Animal subjects: All authors have confirmed that this study did not involve animal subjects or tissue. Conflicts of interest: In compliance with the ICMJE uniform disclosure form, all authors declare the following: Payment/services info: All authors have declared that no financial support was received from any organization for the submitted work. Financial relationships: All authors have declared that they have no financial relationships at present or within the previous three years with any organizations that might have an interest in the submitted work. Other relationships: All authors have declared that there are no other relationships or activities that could appear to have influenced the submitted work.

\section{References}

1. Mangat R, Ho HS, Kuo TL: Non-invasive evaluation of lower urinary tract symptoms (LUTS) in men . Asian J Urol. 2017, 5:42-47. 10.1016/j.ajur.2017.12.002

2. Sagen E: Transurethral resection of the prostate: studies on efficacy, morbidity and costs .

3. Strope SA: Evidence-based guidelines in lower urinary tract symptoms secondary to benign prostatic hyperplasia and variation in care. Curr Opin Urol. 2018, 28:262-266. 10.1097/MOU.0000000000000504

4. Lim KB, Ho H, Foo KT, et al.: Comparison of intravesical prostatic protrusion, prostate volume and serum prostatic-specific antigen in the evaluation of bladder outlet obstruction. Int J Urol. 2006, 13:1509-1513. 10.1111/j.1442-2042.2006.01611.x

5. Wein AJ, Kavoussi LR, Novick AC, Partin AW, Peters CA: Campbell-Walsh urology: expert consult premium edition: enhanced online features and print, 4-volume set. Elsevier Health Sciences, 2015.

6. Malde S, Nambiar AK, Umbach R, et al.: European Association of Urology Non-neurogenic Male LUTS Guidelines Panel. Systematic review of the performance of noninvasive tests in diagnosing bladder outlet obstruction in men with lower urinary tract symptoms. Eur Urol. 2017, 71:391-402. 10.1016/j.eururo.2016.09.026

7. Sakalis V, Sfiggas V, Vouros I, Salpiggidis G, Papathanasiou A, Apostolidis A: Detrusor overactivity may be a prognostic factor for better response to combination therapy over monotherapy in male patients with benign prostatic enlargement and storage lower urinary tract symptoms [Epub ahead of print]. Int Neurourol J. 2020, 10.5213/inj.2040188.094

8. Ma C, Zhang J, Cai Z, Xiong J, Li H: Defining the efficacy and safety of phosphodiesterase type 5 inhibitors with tamsulosin for the treatment of lower urinary tract symptoms secondary to benign prostatic hyperplasia with or without erectile dysfunction: a network meta-analysis. Biomed Res Int. 2020,

9. Crockett MG, Drake MJ: The role of urodynamics in the surgical management of benign prostatic obstruction. Curr Opin Urol. 2018, 28:267-272. 10.1097/MOU.0000000000000496

10. Karavitakis M, Kyriazis I, Omar MI, Gravas S: Management of urinary retention in patients with benign prostatic obstruction: a systematic review and meta-analysis. Eur Urol. 2019, 75:788-798. 10.1016/j.eururo.2019.01.046

11. Lee JW, Ryu JH, Yoo TK, Byun SS, Jeong YJ, Jung TY: Relationship between intravesical prostatic protrusion and postoperative outcomes in patients with benign prostatic hyperplasia. Korean J Urol. 2012, 53:478-482. 10.4111/kju.2012.53.7.478

12. Memon A, Ather MH: Use of residual fraction instead of residual volume in the evaluation of lower urinary tract symptoms. Tech Urol. 2000, 6:26-28.

13. Ather MH, Memon A: Uroflowmetry and evaluation of voiding dysfunction . Tech Urol. 1998, 4:111-117.

14. Gravas S, Cornu JN, Gacci MC, Gratzke C, Herrmann TR, Mamoulakis C: Management of Non-Neurogenic Male LUTS. 2020. https://scholar.google.com/scholar? q=intitle:Management\%20of\%20Non\%E2\%80\%90Neurogenic\%20Male\%20LUTS.

15. Yalla SV, Sullivan MP, Lecamwasam HS, DuBeau CE, Vickers MA, Cravalho EG: Correlation of AmericanUrological Association symptom index with obstructive and nonobstructive prostatism. J Urol. 1995, 153:674-679. 10.1016/S0022-5347(01)67682-1

16. Reynard JM, Peters TJ, Lamond E, Abrams P: The significance of abdominal straining in men with lowerurinary tract symptoms. Br J Urol. 1995, 75:148-153. 10.1111/j.1464-410X.1995.tb07302.x

17. Reynard J, Lim C, Abrams P: Significance of intermittency in men with lower urinary tract symptoms . Urology. 1996, 47:491-496. 10.1016/S0090-4295(99)80483-X

18. Pel JJ, Bosch JL, Blom JH, Lycklama à Nijeholt AA, van Mastrigt R: Development of a non-invasive strategy toclassify bladder outlet obstruction in male patients with LUTS. Neurourol Urodyn. 2002, 21:117-125. 10.1002/nau.10046

19. Jiang YH, Lin VC, Liao CH, Kuo HC: International Prostatic Symptom Score-voiding/storage subscore ratio in association with total prostatic volume and maximum flow rate is diagnostic of bladder outlet-related lower urinary tract dysfunction in men with lower urinary tract symptoms. PLoS One. 2013, 8:e59176. 10.1371/journal.pone.0059176

20. Ball AJ, Feneley RC, Abrams PH: The natural history of untreated prostatism . Br J Urol. 1981, 53:613-616. 


\section{Cureus}

10.1111/j.1464-410X.1981.tb03273.X

21. Van Mastrigt R, Rollema HJ: The prognostic value of bladder contractility in transurethral resection of the prostate. J Urol. 1992, 148:1856-1860. 10.1016/S0022-5347(17)37049-0

22. Rosier PF, de la Rosette JJ: Is there a correlation between prostate size and bladder-outlet obstruction? . World J Urol. 1995, 13:9-13. 10.1007/BF0018658 